\title{
ERRATUM
}

Juliana Oliveira Lima · Jildete Karla dos Santos Jorge Fernando Pereira - Mário Lúcio Vilela de Resende Elza Fernandes de Araújo - Marisa Vieira de Queiroz

\section{Development of a transformation system for Crinipellis perniciosa, the causal agent of witches' broom in cocoa plants}

Published online: 14 March 2003

(C) Springer-Verlag 2003

\section{Current Genetics (2003) 42:236-240}

In the printed version of the article the primer sequences of hph1 and hph2 (Materials and Methods) were wrong. The correct primer sequences of hph1 and hph2 are:

hph1 (5'-CAGCGAGAGCCTGACCTATTGC-3')

hph2 (5'-GCCATCGGTCCAGACGGCCGCGC-3')

The online version of the original article can be found at http:// dx.doi.org/10.1007/s00294-002-0358-Z

J.O. Lima · J.K. dos Santos · J.F. Pereira

E.F. de Araújo · M.V. de Queiroz ( $\square)$

Departamento de Microbiologia/BIOAGRO,

Universidade Federal de Viçosa,

36.570-000 Viçosa, Minas Gerais, Brazil

E-mail: mvqueiro@mail.ufv.br

Tel.: + 55-31-38992553

Fax: + 55-31-38992573

M.L.V. de Resende

Departamen to de Fitopatologia,

Universidade Federal de Lavras,

37.200-000 Lavras, Minas Gerais, Brazil 